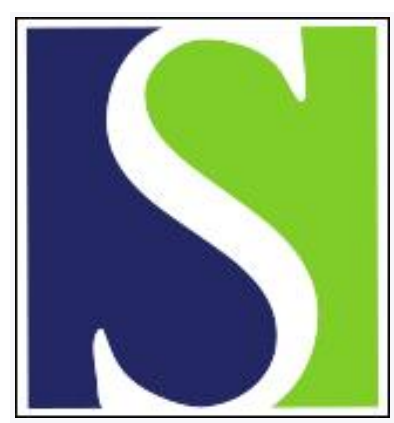

Scand J Work Environ Health 1986;12(6):627-629

https://doi.org/10.5271/sjweh.2092

Issue date: Dec 1986

Acetone-induced changes in the toxicokinetics of 2,5-hexanedione in rabbits.

by Ladefoged O, Perbellini L

This article in PubMed: www.ncbi.nlm.nih.gov/pubmed/3823813

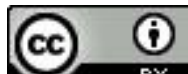




\title{
Acetone-induced changes in the toxicokinetics of 2,5-hexanedione in rabbits
}

\author{
by Ole Ladefoged, PhD', Luigi Perbellini, DMedSc ${ }^{2}$
}

\begin{abstract}
LADEFOGED O, PERBELLINI L. Acetone-induced changes in the toxicokinetics of 2,5-hexanedione in rabbits. Scand J Work Environ Health 12 (1986) $627-629$. Male rabbits were intraveneously injected with 2,5-hexanedione or 2,5-hexanedione plus acetone. A toxicokinetic analysis showed that a twocompartment model satisfactorily described the kinetics of 2,5-hexanedione in rabbits. Simultaneous dosing with acetone altered the toxicokinetic model which best described the plasma concentration versus time data. The model-independent parameter body clearance, calculated according to the trapezoidal rule, showed a decrease in the body clearence of 2,5-hexanedione in rabbits simultaneously injected with acetone. The results suggest that toxicokinetic interference may partly explain the neurotoxic potentiation of that which occurs in 2,5-hexanedione-induced axonopathy as a response to simultaneous exposure to acetone.
\end{abstract}

Key terms: n-hexane, neurotoxicity, potentiation, two-compartment model.

The central-peripheral distal axonopathy caused by long-term exposure to $n$-hexane has been associated with the biotransformation of $n$-hexane to the toxic metabolite 2,5-hexanedione (2,5-HD).

For some years it has been known that the ketone methyl ethyl ketone potentiates the neurotoxicity of $\mathrm{n}$-hexane (2). The mechanism is not fully understood $(9,11)$, but experimental data support the idea that the potentiation is partly due to the persistence of the neurotoxic metabolites in the blood or due to the formation of more of the metabolites of n-hexane, changes in the protein binding of $2,5-\mathrm{HD}$, or changes in the distribution of the metabolites $(9,11)$. In a previous report it has been shown that acetone, another ketone, may also potentiate the neurotoxicity of $2,5-\mathrm{HD}$ in rats (6). In these rats the plasma levels of 2,5-HD were significantly greater in groups dosed with 2,5-HD plus acetone than in 2,5-HD-dosed animals (own unpublished results). Furthermore it has been shown that nonneurotoxic aliphatic monoketones enhance the neurotoxicity of methyl n-butyl ketone, another neurotoxic metabolite of $n$-hexane (7). In addition methyl isobutyl ketone enhances the neurotoxicity of $n$ hexane (1).

The aim of the present study was to determine whether acetone alters the toxicokinetics of 2,5-HD after simultaneous intravenous injection to rabbits and also to determine the toxicokinetic parameters of 2,5-HD in rabbits.

\footnotetext{
1 Department of Chemistry and Toxicology, Danish National Institute of Occupational Health, Baunegaardsvej 73, DK-2900 Hellerup, Denmark.

2 Istituto di Medicina del Lavoro dell'Universita' di Verona, Policlinico Borgo Roma, I-37134 Verona, Italy.
}

Reprint requests to: Dr O Ladefoged, Danish National Institute of Occupational Health, Baunegaardsvej 73, DK-2900 Hellerup, Denmark.

\section{Materials and methods}

The experiments were performed in 12 clinically healthy male rabbits (New Zealand white) weighing $2.0-3.3 \mathrm{~kg}$. Doses of $2,5-\mathrm{HD}(50 \mathrm{mg} / \mathrm{kg})$ or $2,5-\mathrm{HD}$ plus acetone $(150 \mathrm{mg} / \mathrm{kg})$ were given as intravenous injections to the left ears of two groups of six rabbits. About 12 venous blood samples of $1-2 \mathrm{ml}$, stabilized with ethylenediaminetetraacetate (EDTA) were taken from the right ear during the next $5 \mathrm{~min}$ to $12 \mathrm{~h}$. The samples were centrifuged for $20 \mathrm{~min}$ at 2000 revolutions/min, and the plasma concentrations of 2,5-HD were determined.

The analyses of 2,5-HD were performed on $0.5-1.0$ $\mathrm{ml}$ of plasma. The samples were extracted with $5 \mathrm{ml}$ of bidistilled diethylether with $50 \mu \mathrm{g}$ of cyclohexanone added as the internal standard. The extracts were slowly evaporated to $200 \mu \mathrm{l}$, and $3 \mu \mathrm{l}$ was injected for analyses into a C Erba gas chromatograph model 4160 with an SE 54 capillary column, as previously described (8).

\section{Calculations}

A nonlinear iterative curve fitting the computer program AUTOAN (10) was used to analyze the plasma concentrations versus time curves as previously described (5).

The program includes the determination of elimination kinetics, exponential stripping, toxicokinetic model selection, and the initial estimation of model parameters. If the plasma concentration versus time curves could be described by the two-compartment model, $C_{t}=A \cdot e^{-\alpha t}+B \cdot e^{-\beta t}$, the parameters $A, \alpha$, $B$ and $\beta$ were calculated.

The volume of distribution in the central compartment $\left(\mathrm{V}_{1}\right)$ was calculated as follows: $\mathrm{V}_{1}=\mathrm{D} / \mathrm{A}+\mathrm{B}$, $\mathrm{D}=$ dose in milligrams per kilogram of body weight. $\mathrm{V}_{2}$ (volume of distribution in the peripheral compart- 
Table 1. Analysis of the number of exponential terms which best describe the plasma concentration-time data for 2,5-hexanedione (2,5-HD) (50 mg/kg body weight) alone in six rabbits and those for $2,5-\mathrm{HD}(50 \mathrm{mg} / \mathrm{kg}$ body weight) in six rabbits simultaneously injected with acetone $(150 \mathrm{mg} / \mathrm{kg}$ body weight).

\begin{tabular}{lcc}
\hline & \multicolumn{2}{c}{ Number of exponential terms } \\
\cline { 2 - 3 } & 2 & $\geqq 3$ \\
\cline { 2 - 3 } $2,5-\mathrm{HD}$ & $5 / 6$ & $1 / 6$ \\
$2,5-\mathrm{HD}$ plus acetone & $2 / 6$ & $4 / 6$ \\
\hline
\end{tabular}

Table 2. Toxicokinetic parameters of 2,5-hexanedione calculated according to the two-compartment model. $\left(V_{1}=\right.$ volume of distribution in the central compartment, $\mathrm{V}_{2}=$ volume of distribution in the peripheral compartment, $\mathrm{k}_{\mathrm{e}}=$ elimination rate constant, $T / 2$ = half-time, $\mathrm{Cl}_{\text {body }}=$ total body clearance)

\begin{tabular}{|c|c|c|c|c|c|}
\hline Rabbit & $V_{1}(1 / \mathrm{kg})$ & $V_{2}(1 / k g)$ & $k_{e}\left(\min ^{-1}\right)$ & $\mathrm{T} / 2(\min )$ & $\begin{array}{c}\mathrm{Cl}_{\text {body }} \\
\left(\mathrm{ml} \cdot \mathrm{min}^{-1} \cdot \mathrm{kg}^{-1}\right)\end{array}$ \\
\hline $\begin{array}{l}1 \\
2 \\
3 \\
4 \\
5\end{array}$ & $\begin{array}{l}0.70 \\
0.68 \\
0.67 \\
0.58 \\
0.73\end{array}$ & $\begin{array}{l}1.10 \\
0.59 \\
0.60 \\
0.72 \\
0.78\end{array}$ & $\begin{array}{l}0.0213 \\
0.0164 \\
0.0128 \\
0.0237 \\
0.0137\end{array}$ & $\begin{array}{l}33 \\
42 \\
54 \\
29 \\
51\end{array}$ & $\begin{array}{l}0.0149 \\
0.0111 \\
0.0087 \\
0.0138 \\
0.0100\end{array}$ \\
\hline $\begin{array}{l}\text { Mean } \\
\text { SD }\end{array}$ & $\begin{array}{l}0.67 \\
0.06\end{array}$ & $\begin{array}{l}0.76 \\
0.21\end{array}$ & $\begin{array}{l}0.0176 \\
0.0048\end{array}$ & $\begin{array}{l}42 \\
11\end{array}$ & $\begin{array}{l}0.0117 \\
0.0026\end{array}$ \\
\hline
\end{tabular}

Table 3. Body clearance of 2,5-hexanedione (2,5-HD) from six rabbits dosed intravenously with $50 \mathrm{mg} / \mathrm{kg}$ or $50 \mathrm{mg} / \mathrm{kg}$ plus acetone $(150 \mathrm{mg} / \mathrm{kg})$. The clearance was calculated by the trapezoidal rule as $\mathrm{Cl}_{\text {body }}=$ D/AUC $\mathrm{ml} \cdot \mathrm{min}^{-1} \cdot \mathrm{kg}^{-1}$. (AUC $=$ area under the plasma concentration versus time curve)

\begin{tabular}{lcc}
\hline Rabbit & $\begin{array}{c}2,5-\mathrm{HD} \\
\left(\mathrm{ml} \cdot \mathrm{min}^{-1} \cdot \mathrm{kg}^{-1}\right)\end{array}$ & $\begin{array}{c}2,5-\mathrm{HD}+\text { acetone } \\
\left(\mathrm{ml} \cdot \mathrm{min}^{-1} \cdot \mathrm{kg}^{-1}\right)\end{array}$ \\
\hline 1 & 0.0139 & 0.0096 \\
2 & 0.0105 & 0.0101 \\
3 & 0.0084 & 0.0086 \\
4 & 0.0125 & 0.0080 \\
5 & 0.0096 & 0.0057 \\
6 & 0.0101 & 0.0061 \\
\hline Mean & 0.0108 & $0.0080^{*}$ \\
SD & 0.0020 & 0.0018 \\
\hline
\end{tabular}

* $p<0.05$.

ment) was calculated as: $\mathrm{V}_{2}=\mathrm{V}_{1} \cdot \mathrm{k}_{12} / \mathrm{k}_{21}$, where $\mathrm{k}_{12}$ and $\mathrm{k}_{21}$ were the distribution rate constants, $\mathrm{k}_{21}=$ $(\mathrm{A} \beta+\mathrm{B} \alpha) / \mathrm{A}+\mathrm{B}$ and $\mathrm{k}_{12}=\alpha+\beta-\mathrm{k}_{21}-\mathrm{k}_{\mathrm{e}}$. The elimination rate constant was calculated by the formula $\mathrm{k}_{\mathrm{e}}=\alpha \beta / \mathrm{k}_{21}$. The total body clearance $\left(\mathrm{Cl}_{\mathrm{body}}\right)$ was calculated by the formula $\mathrm{Cl}_{\text {body }}=\mathrm{k}_{\mathrm{e}} \cdot \mathrm{V}_{1}$. The elimination half-time was calculated as $\mathrm{T} / 2=$ $0.693 / \mathrm{k}_{\mathrm{e}}$.

Because some of the curves for plasma concentration versus time could not be satisfactorily described by the two- or three-compartment models, the modelindependent parameter total body clearance $\left(\mathrm{Cl}_{\text {body }}\right)$ was calculated by the formula: $\mathrm{Cl}_{\text {body }}=\mathrm{D} / \mathrm{AUC}$. The area under the plasma concentration (c) versus time (t) curve (AUC) for $\mathrm{t} \rightarrow \infty$ was calculated by the trapezoidal rule. Two extrapolations were necessary to calculate the area from $t \rightarrow 0$ and from the last point
(T) $\rightarrow \infty$ :

$$
\int_{\mathrm{T}}^{\infty} \mathrm{c}(\mathrm{t}) \cdot \mathrm{dt}=(\mathrm{CT} / \beta),
$$

where $\beta$ is the slope of the terminal phase of the plasma concentration time curve. The statistical calculations were done in accordance with standard methods, and the results have been given as means and standard deviations. Student's t-test was used to compare the body clearances.

\section{Results}

The analyses of all the data for plasma concentration versus time were performed by the AUTOAN program, and they showed that it was reasonable to assume a two-compartment model for 2,5-HD in rabbits. When the animals were dosed with acetone plus 2,5-HD, the data could not be described well by the models which included less than three exponential terms (table 1).

The toxicokinetic parameters $\mathrm{V}_{1}, \mathrm{~V}_{2}, \mathrm{k}_{\mathrm{e}}, \mathrm{T} / 2$ and $\mathrm{Cl}_{\text {body }}$ of 2,5-HD, as calculated for the five rabbits fitting the two-compartment model, are shown in table 2. As seen from the table, the volume of distributions in the central and peripheral compartments were of equal size. The half-time was very short, only $42 \mathrm{~min}$.

The plasma concentration versus time curves for the rabbits dosed with 2,5-HD plus acetone could not be satisfactorily described by simple compartment models, and the $\mathrm{Cl}_{\text {body }}$ was calculated by the trapezoidal rule to compare the body clearance in the two groups of rabbits. As shown in table 3, a reduction in $\mathrm{Cl}_{\text {body }}$ was seen in rabbits given 2,5-HD plus acetone in comparison to the group given 2,5-HD alone. 


\section{Discussion}

The present results support the theory that part of the potentiation of the neurotoxicity of $2,5-\mathrm{HD}$ by acetone may be explained by toxicokinetic interference between acetone and 2,5-HD. This phenomenon was also suggested recently by Ralston et al (9) for the potentiation of the neurotoxicity of 2,5-HD by methyl ethyl ketone. The effect on $\mathrm{Cl}_{\text {body }}$ was not very marked, but in rat experiments where acetone and 2,5-HD are given with drinking water for several weeks, a slight change in the body clearance of $2,5-\mathrm{HD}$ may more greatly influence the steady-state plasma concentration of 2,5-HD. In the present experiment the plasma concentration of acetone was not determined because of the amount of blood to be drawn, but it is to be expected that the half-time of acetone is rather short. Hence the effect of a bolus intravenous injection of acetone may be of short duration in comparison to the effect seen after dosing with acetone in drinking water. Whether these results can be extrapolated to exposure situations with humans is unclear. There seems to be a certain disagreement concerning the effect of methyl ethyl ketone on the rate of transformation of n-hexane to 2,5-HD (4). No study is available concerning the effect of acetone on the formation of neurotoxic metabolites of $n$-hexane, but acetone potentiates the toxicity of several different compounds and may have a biphasic effect, initial inhibition followed by stimu lation for some compounds (3). The most reasonable explanation for the change in the toxicokinetic model which best described the data in the acetone-dosed animals is an interference of acetone with the elimination of 2,5-HD. Although a change in volume of distribution may act as well. Further investigations are needed to elucidate this problem.

\section{Acknowledgments}

This study was supported by a traveling grant to $\mathrm{O}$ Ladefoged from the European Science Foundation and by the Italian National Research Council (CNR) grant n 840221456 .
The authors wish to acknowledge Ms G Larsen, Ms $\mathrm{K}$ Roswall, and Mr E Holst for their help with the calculations of the results.

\section{References}

1. Abou-Donia MB, Lapadula DM, Campbell G, Timmons $P$. The synergism of $n$-hexane-induced neurotoxicity by methyl isobutyl ketone following subchronic ( 90 days) inhalation in hens: Induction of hepatic microsomal cytochrome P-450. Toxicol Appl Pharmacol 81 (1985) $1-16$.

2. Altenkirch H, Stoltenberg G, Wagner HM. Experimental studies on hydrocarbon neuropathies induced by methylethyl-ketone (MEK). J Neurol 219 (1978) 159-170.

3. Freeman JJ, Hayes EP. Acetone potentiation of acute acetonitrile toxicity in rats. J Toxicol Environ Health 15 (1985) 609-621.

4. Iwata M, Takeuchi Y, Hisanaga N, Ono Y. A study on biological monitoring of n-hexane exposure. Int Arch Occup Environ Health 53 (1983) 1-8.

5. Ladefoged $O$. The absorption half-life, volume of distribution and elimination half-life of trimethoprim after peroral administration to febrile rabbits. Zentralbl Veterinaermed A 26 (1979) 580-586.

6. Ladefoged O, Hass U, Simonsen L. Neurophysiological and behavioral effects of 2,5-hexanedione and acetone in rats. In: Arbetarskyddsverket. ICOST: International conference on organic solvent toxicity, Stockholm, October 15-17, 1984: Abstract book. Stockholm 1984, p 108. (Abstract).

7. Misumi J, Nagano M. Neurophysiological studies on the relation between the structural properties and neurotoxicity of aliphatic hydrocarbon compounds in rats. $\mathrm{Br} \mathrm{J}$ Ind Med 41 (1984) 526-532.

8. Perbellini L, Brugnone F, Silvestri R, Gaffuri E. Measurement of the urinary metabolites of n-hexane, cyclohexane and their isomers by gas chromatography. Int Arch Occup Environ Health 48 (1981) 99-106.

9. Ralston WH, Hildebrand RL, Uddin DE, Andersen ME, Gardier RW. Potentiation of 2,5-hexanedione neurotoxicity by methyl-ethyl-ketone. Toxicol Appl Pharmacol 81 (1985) 319-327.

10. Sedman AJ, Wagner JG. AUTOAN: A decision-making pharmacokinetic computer program. Publication Distribution Service, Ann Arbor, MI 1976.

11. Takeuchi Y, Ono Y, Hisanaga W, Iwata M, Aoyama $M$, Kitoh J. An experimental study of the combined effects of $n$-hexane and methyl ethyl ketone. $\mathrm{Br} J$ Ind Med 40 (1983) $199-203$.

Received for publication: 26 May 1986 